\title{
An Unusual Case of Moraxella osleonsis Bacteremia in an Immunocompetent Patient With SARS-CoV-2 Infection
}

\author{
Bala C. Veerabathini ${ }^{1}$, Kaushik Manthani ${ }^{1}$, Sandeep Gandhi ${ }^{2}$ \\ 1. Family Medicine, Peconic Bay Medical Center-Northwell Health, Riverhead, USA 2. Infectious Disease, Peconic Bay \\ Medical Center-Northwell Health, Riverhead, USA
}

Corresponding author: Sandeep Gandhi, sanganmd@gmail.com

\begin{abstract}
Moraxella osleonsis (M.osleonsis) is an organism that rarely presents with bacteremia in immunocompetent patients. We report a case of an immunocompetent 59-year-old male with a recent SARS-CoV-2 infection that developed M.osleonsis bacteremia. We believe that SARS-CoV-2 infection may have played a role in developing M.osleonsis bacteremia in this patient and may be one of the first reported cases of such bacteremia in a COVID-19 patient.
\end{abstract}

Received 07/27/2020

Review began 08/10/2020 Review ended 08/27/2020 Published 08/31/2020

() Copyright 2020

Veerabathini et al. This is an open access article distributed under the terms of the Creative Commons Attribution License CC-BY 4.0., which permits unrestricted use, distribution, and reproduction in any medium, provided the original author and source are credited.
Categories: Internal Medicine, Psychiatry, Infectious Disease

Keywords: bacteremia, covid-19, coronavirus, moraxella, immunocompetent, immunocompromised, cd-4, cd-8, t cells, regulatory t cells

\section{Introduction}

The species Moraxella osleonsis (M.osleonsis), first described in the literature in 1967, consists of aerobic gram-negative oxidase-positive coccobacilli. In humans, species of the M.osleonsis were found to be inhabitants of the upper respiratory tract [1]. This bacterium has been found in healthy adults' nasopharynx, nose, and oropharynx [1-3]. However, individual reports of infection by this bacterium are rare and, as a result, M.osleonsis has been rarely studied for its clinical significance [1]. It has been reported to cause the following infections: septic arthritis, vaginitis, endocarditis, bacteremia, meningitis, and sinusitis [4-6].

The current coronavirus disease (COVID-19) pandemic caused by the severe acute respiratory syndrome coronavirus 2 (SARS-CoV-2) has emerged to be a cause for many ailments in humans. It is primarily known to affect the respiratory system but also causes cardiovascular disease, renal failure, and sequelae of a hypercoagulable state [7-9]. Being the first novel virus to have affected the human race in recent history, various mechanisms have been recently proposed to explain its effects. While the specific mechanisms are not fully understood, it is becoming more evident that a SARS-CoV-2 infection may be making humans more susceptible to various systemic diseases, including the possibility of causing rare bacteremia.

\section{Case Presentation}

A 59-year-old male with a past medical history of Crohn's disease, hypertension, hyperlipidemia, chronic obstructive pulmonary disease, bipolar disorder, and chronic back pain presented to the hospital with lethargy and vomiting. He had cough, nausea, vomiting and chronic back pain, but he denied chills, headaches, sore throat, diarrhea, loss of taste or smell, shortness of breath and muscle aches. Of note, he had a recent hospitalization for COVID-19 pneumonia two months prior where he was treated with ten days of hydroxychloroquine and five days of azithromycin. The patient reported no residual symptoms from his prior SARS-CoV-2 infection.

Upon admission, the patient reported that he had taken seven unspecified muscle relaxants to help alleviate his back pain. His home medications are listed in Table 1. Home medications were stopped on admission. He was not on any medications for Crohn's disease as he had no symptoms of the disease. 


\section{Cureus}

\begin{tabular}{|c|c|c|}
\hline Medication: & Dosage: & Frequency: \\
\hline Valproic acid & $250 \mathrm{mg}$ & Three times daily \\
\hline Clonazepam & $1 \mathrm{mg}$ & Once daily \\
\hline Olanzapine & $5 \mathrm{mg}$ & Twice daily \\
\hline Trazadone & $100 \mathrm{mg}$ & Once daily \\
\hline Gabapentin & $400 \mathrm{mg}$ & Twice daily \\
\hline Amlodipine & $2.5 \mathrm{mg}$ & Once daily \\
\hline Medical marijuana & Unspecified & Unspecified \\
\hline
\end{tabular}

\section{TABLE 1: Home Medications}

He appeared well-nourished, cooperative, and in no acute distress. He was conscious, alert and oriented to person, place and time, but seemed lethargic. The physical exam was significant for poor dentition but otherwise unremarkable, including a benign abdominal exam and a nonfocal neurological examination. Initial vitals are listed in Table 2 and pertinent lab results on admission are listed in Table 3. COVID-19 PCR test was positive for antigen and COVID-19 IgG antibody test was positive as well. Urine toxicology was positive for benzodiazepines and cannabinoids.

\begin{tabular}{|l|l|}
\hline Vital sign: & Value: \\
\hline Temperature & $98.5^{\circ} \mathrm{F}$ \\
Blood pressure & $108 / 71 \mathrm{~mm} \mathrm{Hg}$ \\
Pulse & 69 beats $/ \mathrm{min}$ \\
Respiratory rate & $16 / \mathrm{min}$ \\
\hline Oxygen saturation & $100 \%$ on room air \\
\hline
\end{tabular}

TABLE 2: Initial Vital Signs 


\section{Cureus}

\begin{tabular}{|c|c|c|}
\hline & Lab value: & Normal range: \\
\hline White blood cell (WBC) count & $4,000 / \mathrm{mm}^{3}$ & 4,500 to $11,000 / \mathrm{mm}^{3}$ \\
\hline Neutrophils & $80.4 \%$ & 54 to $62 \%$ \\
\hline Valproic acid level & $140.90 \mathrm{ug} / \mathrm{mL}$ & 50 to $100 \mathrm{ug} / \mathrm{mL}$ \\
\hline Ammonia & $49.7 \mu / \mathrm{dL}$ & 15 to $45 \mu / d L$ \\
\hline Blood urea nitrogen (BUN) & $19 \mathrm{mg} / \mathrm{dL}$ & 7 to $20 \mathrm{mg} / \mathrm{dL}$ \\
\hline Creatinine & $1 \mathrm{mg} / \mathrm{dL}$ & .6 to $1.2 \mathrm{mg} / \mathrm{dL}$ \\
\hline Total protein & $6.3 \mathrm{~g} / \mathrm{dL}$ & 6.0 to $7.8 \mathrm{~g} / \mathrm{dL}$ \\
\hline Albumin & $3.7 \mathrm{~g} / \mathrm{dL}$ & 3.5 to $5.5 \mathrm{~g} / \mathrm{dL}$ \\
\hline Alkaline phosphatase (ALP) & $43 \mathrm{U} / \mathrm{L}$ & 30 to $100 \mathrm{U} / \mathrm{L}$ \\
\hline Aspartate aminotransferase (AST) & $12 \mathrm{U} / \mathrm{L}$ & 8 to $40 \mathrm{U} / \mathrm{L}$ \\
\hline Alanine aminotransferase (ALT) & $<5 \mathrm{U} / \mathrm{L}$ & 8 to $40 \mathrm{U} / \mathrm{L}$ \\
\hline COVID-19 IgG antibody level & $18.9 \mathrm{~g} / \mathrm{L}$ & $<1 \mathrm{~g} / \mathrm{L}$ \\
\hline
\end{tabular}

\section{TABLE 3: Lab Results}

His initial infectious disease workup on day one was negative. On day two, one blood culture became positive for M.osleonsis and Streptococcus species (salivarius, vestibularis). He was started on 1 gram of intravenous ceftriaxone daily for 14 days, and repeat blood cultures on day four revealed no growth.

The following imaging studies were done. A chest X-ray showed no acute cardiopulmonary disease findings (Figure 1). CT of the chest showed mild right apical paraseptal and centrilobular emphysematous change and dependent atelectatic changes at lung bases (Figure 2). CT of the brain showed no acute intracranial hemorrhage or mass effect from vasogenic edema (Figure 3). Transthoracic echocardiogram showed no vegetations with a left ventricular ejection fraction of $60 \%$ (Figure 4).

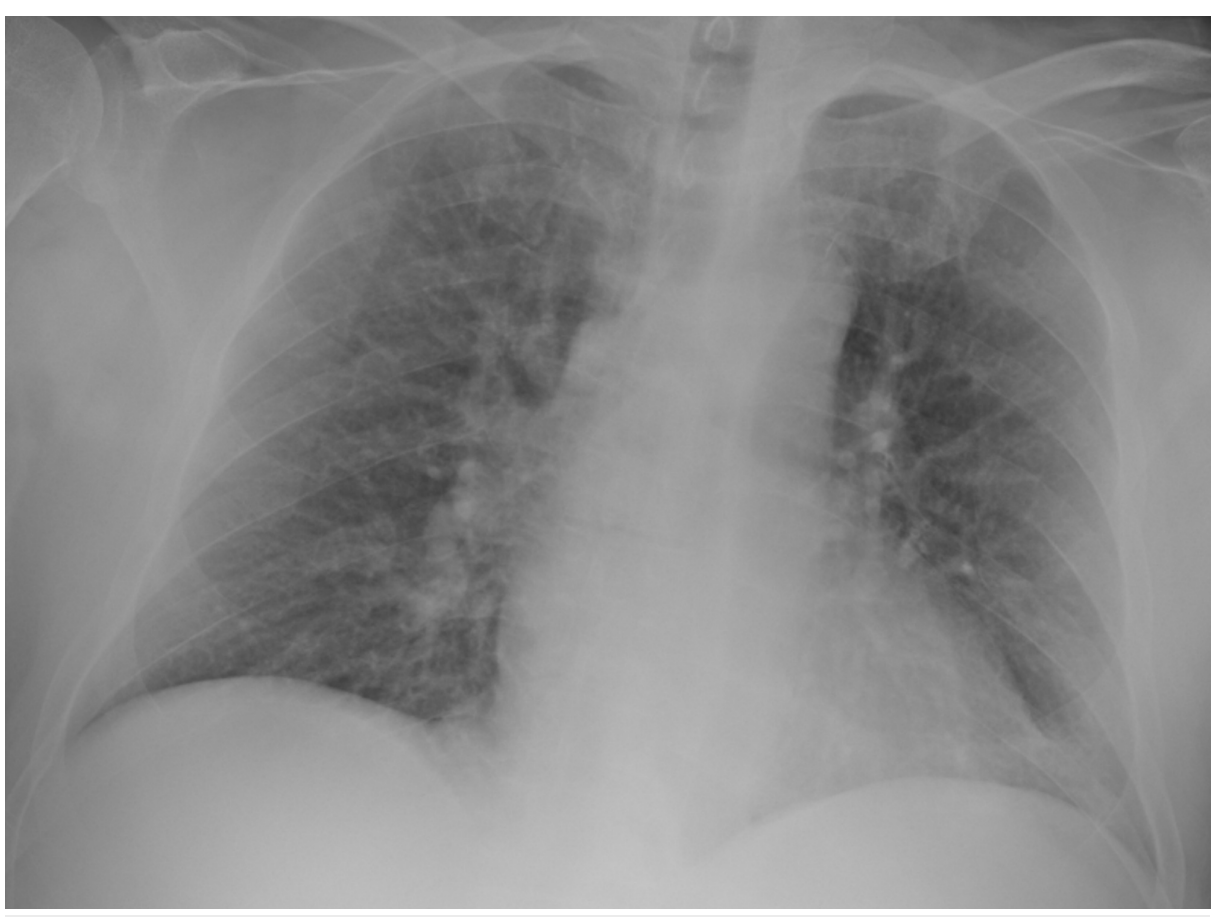

FIGURE 1: X-ray of the Chest (coronal view) 


\section{Cureus}

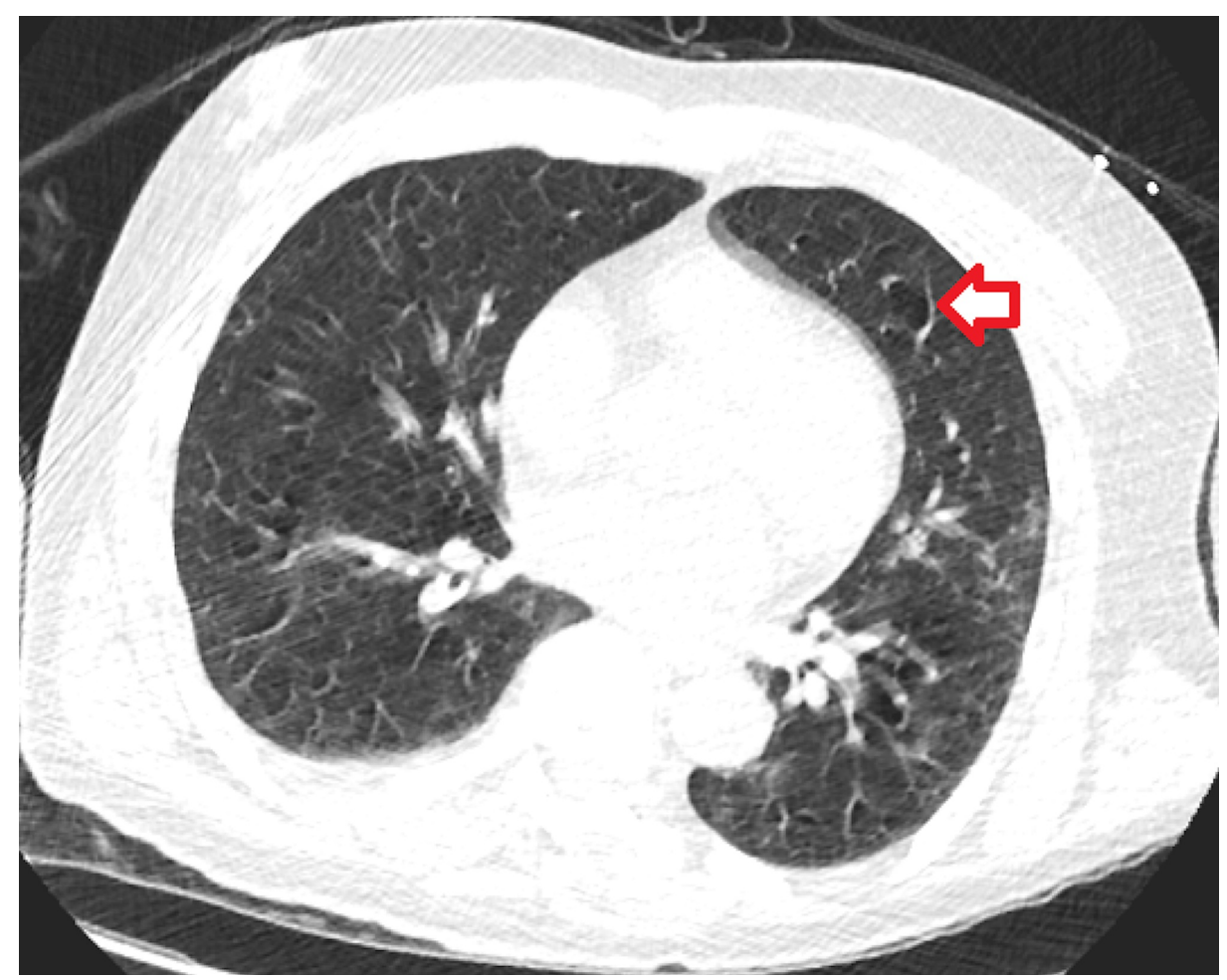

FIGURE 2: Computed Tomography of the Chest Without Contrast (axial view)

Leftwards facing red arrow shows the emphysematous changes.

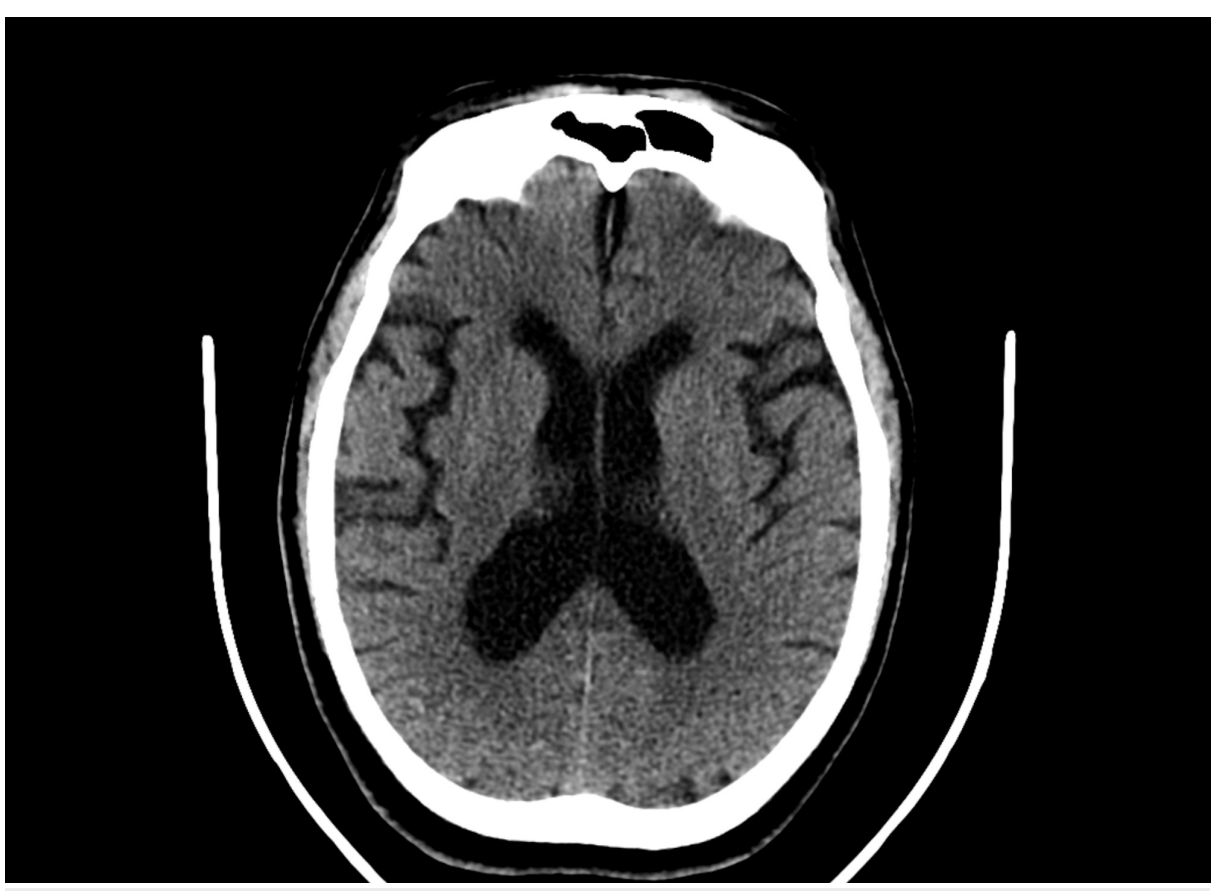

FIGURE 3: Computed Tomography of the Brain Without Contrast (axial view) 


\section{Cureus}

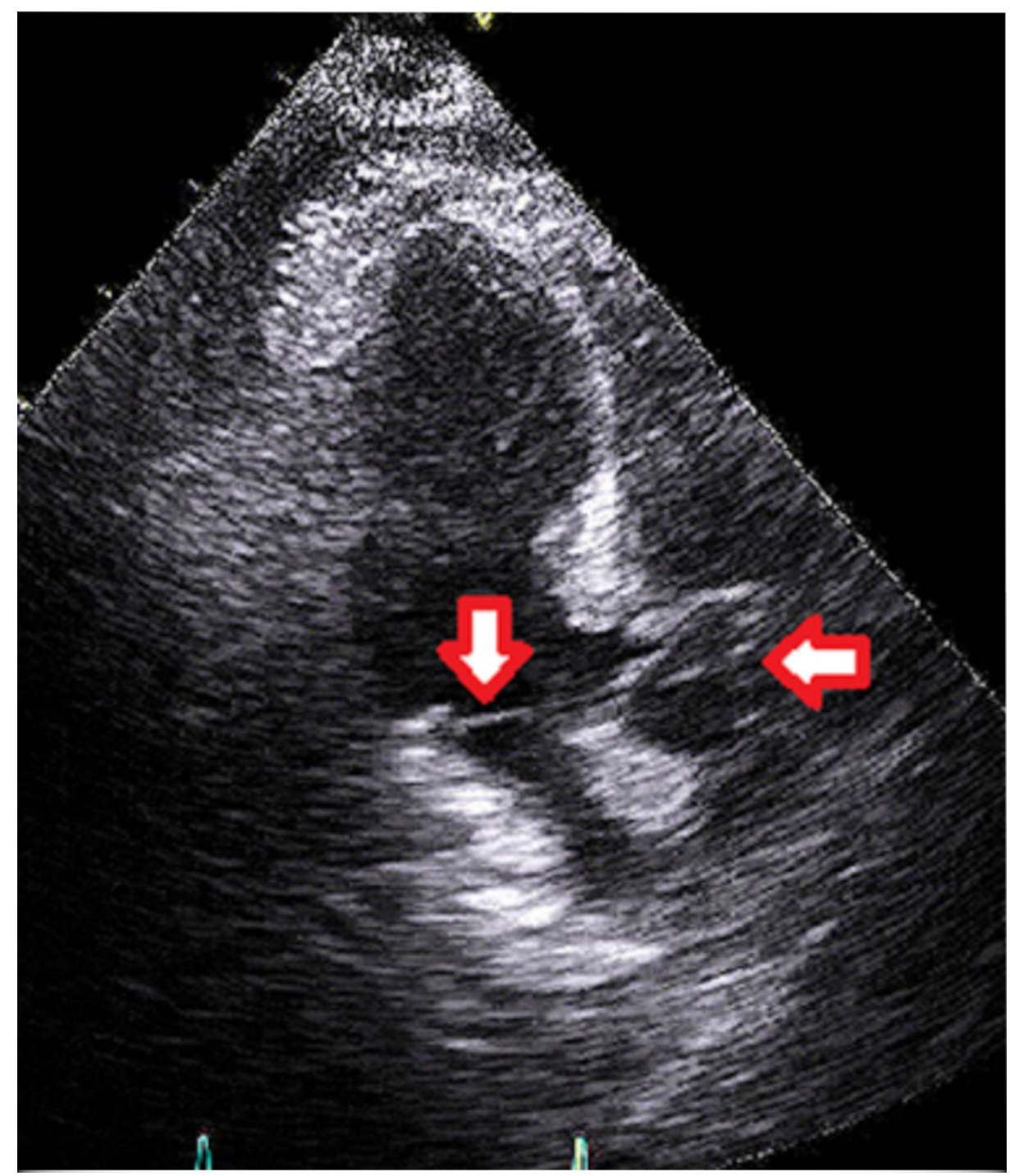

FIGURE 4: Transthoracic Echocardiogram (apical three-chamber view)

Downwards facing red arrow shows the mitral valve, without any vegetations. Leftwards facing red arrow shows the aortic valve, also without vegetations.

As mentioned, he continued intravenous ceftriaxone throughout his hospital stay. Valproic acid was restarted on day three once the valproic acid level was therapeutic. His encephalopathy improved drastically over time and the patient was discharged on day six. On discharge, he was prescribed an eighth-day course of intravenous ceftriaxone for completion of the antibiotic regimen. Dental evaluation, infectious disease, and psychiatry appointments were scheduled for outpatient follow-ups.

\section{Discussion}

Polypharmacy and medication side effects are an important consideration when developing differentials for patient symptoms. This patient was taking several potent psychiatric medications, including valproic acid, clonazepam, trazodone, and olanzapine, which can cause lethargy, encephalopathy, and vomiting [10-12]. Despite normal kidney and liver function tests, hyperammonemia was present in this patient due to supratherapeutic valproic acid levels. Symptoms of valproic acid toxicity can result in central nervous system depression, respiratory depression, metabolic abnormalities, nausea, vomiting, diarrhea, miosis, agitation, tremors, and myoclonus. Symptoms of hyperammonemia can include vomiting, ataxia, behavioral changes, lethargy, somnolence, and coma [12].

Beyond medication-related encephalopathy, other etiologies were sought, including bacteremia, which was ultimately positive for rare bacteria: M.osleonsis.

From 1953 to 1980, the Centers for Disease Control and Prevention has received 199 isolates that were later identified as M.osleonsis. The isolates consisted of specimens mostly from blood, cerebrospinal fluid, ear, 
nose, throat, urine, and genital secretions [13]. As our patient was found to have poor dentition upon physical exam, this may be the site of entry for M.osleonsis bacteremia. While he did have lethargy, nausea, and vomiting, he did not present with other signs and symptoms that may present in bacteremia such as fever, chills, tachypnea, tachycardia, or increased white blood cell (WBC) count. This may be due to effective cephalosporin treatment in its early stages.

Several recent clinical trials have suggested that SARS-CoV-2 infection causes a functional decline of CD8+ T cells and natural killer cells (NK) due to continuous stimulation from the virus [14-17]. According to a study in Wuhan, China, 19 patients in the intensive care unit who were confirmed to have COVID-19 pneumonia had considerably decreased CD4+ and CD8+ T cell levels [14,17]. Another study also found decreased absolute numbers of $\mathrm{T}$ lymphocytes (CD4+ T cells, and CD8+ T cells) in both mild and severe cases of COVID-19 pneumonia, but to a higher degree in the severe cases. CD8+ T cells and B cells were noted to be decreased with an increase in the CD4+/CD8 + ratio in treated COVID-19 patients and were associated with poor treatment outcome [18]. CD4+ and CD8+ T cells play a crucial role in immune response against viral infections and may play a role in vaccine design and long-term immunity. CD8+ T cells release interferons (INF- $\mathrm{Y}$ ), perforin, and granzymes to eliminate viruses, while CD4+ helper T cells enhance CD8+ cells and B cells to help them clear the viral pathogen [14-15,17].

In a recent case report, this is illustrated in a COVID-19 patient with diabetes mellitus, methicillinsensitive Staphylococcus aureus (MSSA) bacteremia and osteomyelitis [17]. CD4+ and CD8+ T cell functional exhaustion may explain the reason why the patient in that case report presented with recurrent bacteremia and multi-organ infection. Despite aggressive antibiotic therapy, the patient remained with bacteremia and developed endocarditis with subsequent aortic root abscess [17]. Leukopenia was present in our patient which may be indicative of depleted T cells. Unfortunately, the CD4+/CD8+ T cell levels were not obtained for our patient, but it may suggest a way that SARS-CoV-2 infection could result in an immunosuppressed state and result in rare bacteremia, especially given that the patient was not taking any immunosuppressant medications or having immunocompromising conditions such as cancer or diabetes.

Current therapeutic treatments for COVID-19 have included immune regulation and developing antibodies for vaccines. Regulatory $\mathrm{T}$ cells (Tregs) offer another alternative therapy. Tregs are believed to be from the same lineage as CD4+ cells and may possibly be reduced in patients with COVID-19. Tregs play a role in regulating or suppressing other cells in the immune system. According to current literature, the level of peripheral Tregs is significantly reduced in severely affected COVID-19 patients compared to mild disease. It has been hypothesized that Tregs migrate to the lungs during tissue injury and cause peripheral reduction. Reduction in the levels of Tregs in the periphery could be associated with an overactive immune system, and in turn damaged lungs, in severely ill COVID-19 patients. One team of scientists has proposed that CD4+CD25+FoxP3+ regulatory T cell-based therapies may be beneficial. Ex vivo transplantation of polyclonal Tregs as well as allogeneic HLA-matched umbilical cord-derived Tregs have shown some positive results in COVID-19 patients [19]. Particularly, two critically ill men with coronavirus who were treated with Tregs from umbilical cord blood showed clinical improvements soon after their first infusion with Tregs, to the point that they were able to be eventually extubated with subsequent tracheostomies in place [20].

\section{Conclusions}

Based on the currently published data, this is the first reported case of M.osleonsis bacteremia in a COVID19 positive patient. M.osleonsis has been shown to affect immunocompromised patients including those with lung cancer or kidney transplants, but rarely presents with bacteremia in immunocompetent patients. This raises the question of whether the presence of a recent SARS-CoV- 2 infection (or the presence of current COVID-19 antigen positivity) creates an immunocompromised state that predisposes patients to bacteremia. More studies will need to be done in order to understand those specific mechanisms of COVID-19 that allow for bacterial translocation into circulation and developing bacteremia. Current therapies for COVID-19 have varied, and further understanding of $\mathrm{T}$ cell regulation in COVID-19 patients may provide more robust treatments in the future.

\section{Additional Information \\ Disclosures}

Human subjects: Consent was obtained by all participants in this study. Conflicts of interest: In compliance with the ICMJE uniform disclosure form, all authors declare the following: Payment/services info: All authors have declared that no financial support was received from any organization for the submitted work. Financial relationships: All authors have declared that they have no financial relationships at present or within the previous three years with any organizations that might have an interest in the submitted work. Other relationships: All authors have declared that there are no other relationships or activities that could appear to have influenced the submitted work.

\section{Acknowledgements}

We would like to express our sincere gratitude to Dr. Andrew Persits for providing guidance on the echocardiogram image. 


\section{References}

1. Shah SS, Ruth A, Coffin SE: Infection due to Moraxella osloensis: case report and review of the literature . Clin Infect Dis. 2000, 30:179-181. 10.1086/313595

2. Berger U, Felsen E: Distribution of species of Moraxella and Moraxella-like organisms in the nasopharynx of healthy human adults. Med Microbiol Immunol. 1976, 162:239-249. 10.1007/BF02121002

3. Bøvre K: Oxidase positive bacteria in the human nose incidence and species distribution, as diagnosed by genetic transformation. Acta Pathol Microbiol Immunol Scand B. 1970, 78:780-784. 10.1111/j.16990463.1970.tb04369.x

4. Fox-Lewis A, Coltart G, Rice S, et al.: Extensive subclinical sinusitis leading to Moraxella osloensis meningitis. IDCases. 2016, 6:39-42. 10.1016/j.idcr.2016.08.007

5. Gagnard JC, Hidri N, Grillon A, Jesel L, Denes E: Moraxella osloensis, an emerging pathogen of endocarditis in immunocompromised patients?. Swiss Med Wkly. 2015, 145:w14185. 10.4414/smw.2015.14185

6. Bard JD, Lewinski M, Summanen PH, Deville JG: Sepsis with prolonged hypotension due to Moraxella osloensis in a non-immunocompromised child. J Med Microbiol. 2011, 60:138-141. 10.1099/jmm.0.016378-0

7. Bansal M: Cardiovascular disease and COVID-19. Diabetes Metab Syndr. 2020, 14:247-250. 10.1016/j.dsx.2020.03.013

8. Durvasula R, Wellington T, Mcnamara E, Watnick S: COVID-19 and kidney failure in the acute care setting: our experience from Seattle. Am J Kidney Dis. 2020, 76:4-6. 10.1053/j.ajkd.2020.04.001

9. Becker RC: COVID-19 update: COVID-19-associated coagulopathy. J Thromb Thrombolysis. 2020, 50:54-67. 10.1007/s11239-020-02134-3

10. Minkel J, Krystal AD: Optimizing the pharmacologic treatment of insomnia: current status and future horizons. Sleep Med Clin. 2013, 8:333-350. 10.1016/j.jsmc.2013.06.002

11. Miller DD: Atypical antipsychotics: sleep, sedation, and efficacy. Prim Care Companion J Clin Psychiatry. 2004, 6:3-7.

12. Chateauvieux S, Morceau F, Dicato M, Diederich M: Molecular and therapeutic potential and toxicity of valproic acid. J Biomed Biotechnol. 2010, 2010: 10.1155/2010/479364

13. Graham DR, Band JD, Thornsberry C, Hollis DG, Weaver RE: Infections caused by Moraxella, Moraxella urethralis, Moraxella-like groups M-5 and M-6, and Kingella kingae in the United States. Clin Infect Dis. 1990, 12:423-431. 10.1093/clinids/12.3.423

14. Diao B, Wang C, Tan Y, et al.: Reduction and functional exhaustion of T-cells in patients with coronavirus disease 2019 (COVID-19). Front Immunol. 2020, 11:1-14. 10.1101/2020.02.18.20024364

15. Ganji A, Farahani I, Khansarinejad B, Ghazavi A, Mosayebi G: Increased expression of CD8 marker on T-cells in COVID-19 patients. Blood Cells Mol Dis. 2020, 83:102437. 10.1016/i.bcmd.2020.102437

16. Zheng M, Gao Y, Wang G, et al.: Functional exhaustion of antiviral lymphocytes in COVID-19 patients . Cell Mol Immunol. 2020, 17:533-535. 10.1038/s41423-020-0402-2

17. Choudhury I, Han H, Manthani K, Gandhi S, Dabhi R: COVID-19 as a possible cause of functional exhaustion of CD4 and CD8 T-cells and persistent cause of methicillin-sensitive Staphylococcus aureus bacteremia. Cureus. 2020, 12(7):e9000. 10.7759/cureus.9000

18. Wang F, Nie J, Wang H, et al.: Characteristics of peripheral lymphocyte subset alteration in COVID-19 pneumonia. J Infect Dis. 2020, 221:1762-1769. 10.1093/infdis/jiaa150

19. Stephen-Victor E, Das M, Karnam A, Pitard B, Gautier J, Bayry J: Potential of regulatory T cell-based therapies in the management of severe COVID-19. European Respiratory Journal. 2020, 56:10.1183/13993003.02182-2020

20. Abbasi J: Regulatory T cells tested in patients with COVID-19 ARDS . JAMA. 2020, 324:539. 10.1001/jama.2020.13765 